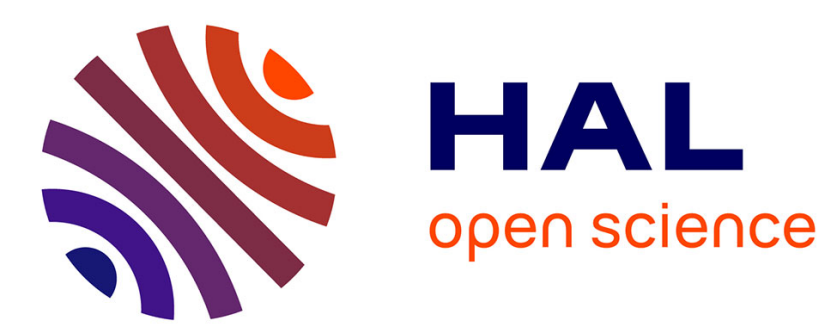

\title{
Solvent Effects on the Intramolecular Spin Exchange in Biradicals at Room Temperature
}

van Anh Tran, Kenneth Rasmussen, Günter Grampp, Alexander Kokorin

\section{To cite this version:}

van Anh Tran, Kenneth Rasmussen, Günter Grampp, Alexander Kokorin. Solvent Effects on the Intramolecular Spin Exchange in Biradicals at Room Temperature. Molecular Physics, 2008, 105 (15-16), pp.2119-2125. 10.1080/00268970701651714 . hal-00513144

\section{HAL Id: hal-00513144 \\ https://hal.science/hal-00513144}

Submitted on 1 Sep 2010

HAL is a multi-disciplinary open access archive for the deposit and dissemination of scientific research documents, whether they are published or not. The documents may come from teaching and research institutions in France or abroad, or from public or private research centers.
L'archive ouverte pluridisciplinaire HAL, est destinée au dépôt et à la diffusion de documents scientifiques de niveau recherche, publiés ou non, émanant des établissements d'enseignement et de recherche français ou étrangers, des laboratoires publics ou privés. 


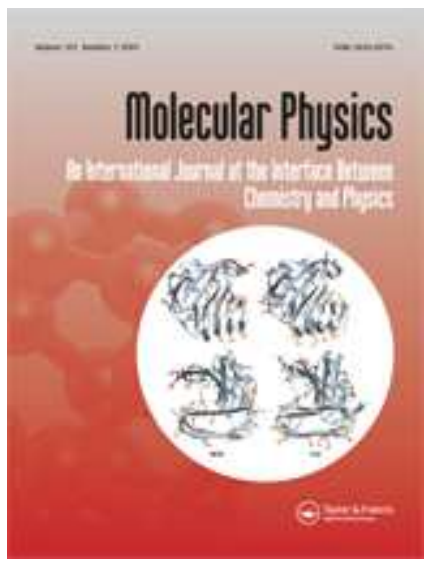

\section{Solvent Effects on the Intramolecular Spin Exchange in Biradicals at Room Temperature}

\begin{tabular}{|r|l|}
\hline Journal: & Molecular Physics \\
\hline Manuscript ID: & TMPH-2007-0186.R1 \\
\hline Manuscript Type: & Full Paper \\
\hline Date Submitted by the & 22-Aug-2007 \\
\hline Complete List of Authors: & $\begin{array}{l}\text { TRAN, Van Anh; Graz University of Technology, Institute of Physical } \\
\text { and Theoretical Chemistry } \\
\text { Rasmussen, Kenneth; Graz University of Technology, Institute of } \\
\text { Physical and Theoretical Chemistry } \\
\text { Grampp, Günter; Graz University of Technology, Institute of } \\
\text { Physical and Theoretical Chemistry } \\
\text { Kokorin, Alexander; Russian Academy of Science, N. Semenov } \\
\text { Institute of Chemical Physics }\end{array}$ \\
\hline Keywords: & $\begin{array}{l}\text { Intramolecular spin exchange, biradicals, solvent effects, ionic } \\
\text { liquid, electron spin resonance }\end{array}$ \\
\hline \hline
\end{tabular}

\section{S ScholaroNE \\ Manuscript Central}


Abstract:

$\dagger$ Institute of Physical and Theoretical Chemistry, Graz University of Technology, Austria † N. Semenov Institute of Chemical Physics, Russian Academy of Science, Moscow Russian Federation

*Corresponding author. Email: vananh@ptc.graz.at

Solvent effects on intramolecular electron spin exchange in biradicals have been investigated in various solvents by electron spin resonance (ESR) spectroscopy at room temperature. Biradicals containing different radical fragments and bridges of different length and composition have been used. Interactions between solvent molecules and biradicals were found to take place at the radical fragment as well as at the functional group in the connecting bridge and have been proved to have an influence on the intramolecular spin exchange. The experimentally measured parameters, exchange integral $(J)$ and characteristic time of an intramolecular movement $\left(\tau_{\text {eff }}\right)$, have been compared with solvent viscosity and polarity parameters (macroscopic level) and longitudinal solvent relaxation time (microscopic level). The dependencies on viscosity and polarity were in good agreement with reported results. In addition, strong evidence of hydrogen bonding between solvent and different sites of the biradicals was found, in some cases even surpassing the other effects.

Keywords: Intramolecular spin exchange, biradicals, solvent effects, ionic liquid

\section{Introduction}

Intramolecular spin exchange in nitroxide biradicals has been under investigation for decades and an extensive literature has been gathered [1-8]. ESR spectroscopy has delivered information about the spin exchange, as an ESR spectrum of a biradical is strongly dependent on the exchange integral value, $J$, which owes to interactions between the two radical fragments of the molecule. It has been shown that the structure of the radical fragments themselves, as well as that of the bridge, which connects them, not only has an influence on $J$, but also on the way the spin exchange takes place [1, 9]. 
In more recent years, the attention has been turned towards the influence of the solvent on the spin exchange. The interaction of solvent molecules with paramagnetic $>\mathrm{N}-\mathrm{O} \cdot$ fragments results in a change of the hyperfine splitting constant $a$ [10-15]. The analysis of ESR spectra of several radicals and biradicals dissolved in various solvents showed certain temperature dependent changes of $a$ which were not sensitive to the solvent polarity, but depended on the composition of the radical fragment $[2,15,16]$. In biradicals with short rigid bridges containing a heteroatom, it was further demonstrated that solvent interactions with the bridge has an influence on the spin exchange [17]. For biradicals with long flexible bridges (i.e. chains of more than 7-8 fragments of - $\mathrm{CH}_{2-},-\mathrm{NH}-$, -O, etc.) analogues with intermolecular spin or self-exchange have been sought as the role of the solvent on this type of reactions is relatively well described $[18,19]$. Here, the relevant solvent parameters include viscosity, polarity and dielectric relaxation parameters and a few indicators that they may also influence intramolecular spin exchange have already been found [20].

This paper reports on additional findings, using biradicals with bridges of different lengths and structure. Various solvents, including the ionic liquid 1-butyl-3-methylimidazolium hexafluorophosphate were used and the spin exchange descriptors in these were determined.

\section{Experimental}

The studied biradicals, RNHCO- $\left(\mathrm{CH}_{2}\right)_{5}-\mathrm{CONHR}$ (I), ROCO- $\left(\mathrm{CH}_{2}\right)_{4}-\mathrm{S}-\left(\mathrm{CH}_{2}\right)_{4}-\mathrm{COOR}$ (II), $\mathrm{R}^{\prime}-\left(\mathrm{CH}_{2}\right)_{4}-\mathrm{R}^{\prime}$ (III), R- $\left(\mathrm{CH}_{2}\right)_{4}-\mathrm{R}$ (IV), R-O-SO-O-R (V), and R-O-S-O-R (VI), were synthesized as described in the literature [21-24]. Their melting points were in good correlation with the published ones. The paramagnetic fragments $-\mathrm{R}$ and $-\mathrm{R}$ ' are shown in Figure 1

\section{[insert Figure 1 about here]}

For the investigation of the solvent effect, different alcohols were chosen together with the reference solvent toluene. The latter is known as being inert with respect to specific solvent-solute interactions and additionally large amounts of data on intramolecular dynamics in other biradical systems have been collected. Furthermore the ionic liquid 1-butyl-3-methylimidazolium hexafluorophosphate $\left(\right.$ bmimPF $\left._{6}\right)$ was used. This solvent was chosen because of the interesting behaviors of well- studied solvent polarity probes in it. It was reported that the polarity of bmimPF is similar to that of methanol [25]. In contrast, bmimPF 6 has very high viscosity and remains a liquid over a large range of temperature may reveal information intramolecular motion, which is should be much slower than that in other traditional solvents. The physical properties of the solvents are presented in table 1.

\section{[insert table 1 about here].}

All solvents were of the highest commercially available grade, subsequently purified and dried over suitable molecular sieves according to literature procedures [26]. BmimFP $_{6}(\geq 98.5 \%)$ was purchased from Fluka. Before use it was dried at $60^{\circ} \mathrm{C}$ under reduced pressure and finally under high vacuum $\left(4 \cdot 10^{-3} \mathrm{mbar}\right)$ in order to remove water. Solutions were prepared, bubbled with nitrogen for 15-20 min., after which $0.5 \mathrm{ml}$ was taken to a thin capillary under nitrogen, degassed by freeze pump - thaw cycles to remove molecular oxygen, and finally sealed off under vacuum. In the cases of 1-octanol, cyclohexanol, and bmimPF $_{6}$, solutions were heated slightly while bubbling. Radical concentrations were kept sufficiently low $\left(\leq 5 \cdot 10^{-4} \mathrm{M}\right)$ to eliminate intermolecular exchange broadening [9].

ESR spectra were recorded using a modulation frequency of $100 \mathrm{kHz}$ at $\mathrm{X}$-band on a Bruker ELEXSYS 560 series spectrometer equipped with a temperature control system (accuracy $\pm 0.5 \mathrm{~K}$ ). For each experimental spectrum, the hyperfine splitting constant $a$ as well as the line positions, widths and intensities were measured.

\section{Results and Discussions}

In liquid solutions with low viscosity, the dipole-dipole interactions between unpaired electrons, as well as the anisotropic hyperfine and Zeeman interactions are practically completely averaged to 
where $\tau_{1}$ and $\tau_{2}$ are the characteristic lifetimes of the two conformations.

For flexible rather long-chained bridges (Biradicals I and II), the influence of the solvent molecules can be discussed as the presence of a "cage effect" $[1,31]$. Temperature changes of the quintet spectra for these biradicals are typical for the case, where the biradicals exist in three conformations: an "elongated" conformation A with $J_{\mathrm{A}}=0$ (and lifetime $\tau$ ), and two conformations $\mathrm{B}$ and $\mathrm{C}$ (with total lifetime $\tau_{\mathrm{C}}$ ), in which the radical fragments are near by each other inside the solvent "cage", but with $J_{\mathrm{B}}=0$, and $\left|J_{\mathrm{C}}\right|>>a$ [31]. The resulting ESR spectra may then be viewed as the superposition of two spectra, of which one corresponds to conformation A and the other to conformations $\mathrm{B}$ and $\mathrm{C}$. The observed line narrowing is caused by fast transitions between the conformations $\mathrm{B}$ and $\mathrm{C}$ inside the cage. Additional exchange effects caused by conformation $\mathrm{A}$ maybe neglected as transitions from the outside (A) to the inside of the cage (B and C) are slow i.e., $\left\{\right.$ a.max $\left.\left(\tau, \tau_{\mathrm{C}}\right)\right\}>1$ [1,30]. This model allows one to obtain information about the motion of the radical fragments inside the cage. In the case of the fast modulation of the exchange interaction, the exchange broadening $1 / T_{2}$ of these lines is described by the expression [1,30]:

$$
1 / T_{2}=a^{2} \tau_{\text {eff }} / 4
$$

where $\tau_{\text {eff }}$ is a complex combination of the modulation parameters and its value is close to the longest of characteristic times of the intramolecular motions. For Lorentzian lines, $\tau_{\mathrm{eff}}$ may be calculated according to eq. 3 [31]:

$$
\tau_{\text {eff }}=2 \sqrt{3}\left|\gamma_{e}\right|\left(\Delta B_{2}-\Delta B_{1}\right) / a^{2}
$$

Here $a$ is taken in frequency units, $\gamma_{\mathrm{e}}$ is the magnetogyric ratio of the free electron, and $\Delta B_{1}$ and $\Delta B_{2}$ are peak-to-peak linewidths of the first and second lines of ESR spectra.

\section{[insert Figure 2 about here]}

Typical ESR spectra of the six biradicals studied here are shown in Figure 2. Three of these, I, II and III, have spectra which are characteristic for biradicals where the cage effect is present and thus $\tau_{\text {eff }}$ values can be determined for them. For the remaining three, which all have short bridges, $J$ was determined using the line positions in the corresponding ESR spectra. Due to the flexibility of their 
bridges, IV and VI are considered to exist in two conformations [1,19] whereas $\mathbf{V}$, where the bridge is rigid, exists in only one [17]. The effect of the structure of the radical fragment can be seen from a comparison of III and IV. These biradicals have identical bridges but show different behaviour. Experimentally, the parameters $\tau_{\text {eff }}$ or $J$ have been calculated from ESR spectra and the obtained results are presented in the table 2.

[insert table 2 about here ].

It has been suggested that solvent viscosity has an effect on the intramolecular movement in biradicals [17,19] and to confirm this point, the experimentally determined parameters $\tau_{\text {eff }}$ and $J$ have been compared with viscosities, $\eta$ of different solvents at $25^{\circ} \mathrm{C}$ (Figure 3).

\title{
[insert Figure 3 about here]
}

As seen in Figure 3, similar viscosity dependence could indeed be observed for I and II where a significant increase of $\tau_{\text {eff }}$ was observed with increasing viscosity. III, IV and VI, with their short flexible bridges, show a similar behaviour, but the viscosity dependence is less prominent. Note that for IV the exchange integral decreases with increasing viscosity whereas that of VI increases, thereby indicating different dependencies of the characteristic life times $\tau_{1}$ and $\tau_{2}$ for the two conformations existing of each biradical. The exchange integrals themselves do not change significantly as can be seen for $\mathbf{V}$, which is the only rigid biradical, where the experimental $J$ is practically independent of viscosity. This can be explained by non-diffusion control of conformational transitions. Since the bridges are short, the intramolecular spin exchange occurs not by direct collisions of the nitroxide $>\mathrm{N}-\mathrm{O}$ - fragments, but via the ,indirect" mechanism of exchange with overlapping of orbitals of the unpaired electrons, mainly localized in the $>\mathrm{N}-\mathrm{O}$ - bond $[19,32]$. It should be noted, that for some solvents the values shown are obtained by extrapolations, since the spin exchange could not be registered at $25^{\circ} \mathrm{C}$. This, however, should not influence the interpretations made here, as the temperature dependencies of $\tau_{\text {eff }}, J$ and $\eta$, along with several other solvent properties, are all exponential. With this, extrapolations made should still be good representations of the experimental data, at least as long as the extrapolations are relatively short. The ionic liquid, bmimPF$_{6}$, which was used with $\mathbf{I}$, is the only solvent where the correlation clearly fails. Here the extrapolation was made over almost $100 \mathrm{~K}$ which is likely to exhaust the applicability of the exponential model of the viscosity and possibly also of $\tau_{\text {eff. }}$.

When investigating the influence of solvent polarity on a chemical reaction the most widely used parameters are Dimroth and Reichardt's $\mathrm{E}_{\mathrm{T}}(30)$ [34] and Kamlet and Taft's $\pi^{*}[35,36]$. The latter has the advantage that it does not include the hydrogen bonding abilities of the solvent, which according to Kamlet and Taft is in stead accounted for by the parameter $\alpha$. Thus, a separation of the different effects is possible. These parameters are known for a large number of solvents (see table 1) and have been related to each other, empirically, by Marcus [32]:

$$
E_{T}(30)=15.2 \alpha+11.6 \pi^{*}+31.2
$$

\begin{abstract}
Note that in ionic liquids, in addition to hydrogen bonding, specific ionic interactions between solvent and solute are possible and since $\alpha$ is often determined indirectly, via $\mathrm{E}_{\mathrm{T}}(30)$ and $\pi^{*}$, these can not be separated [37].

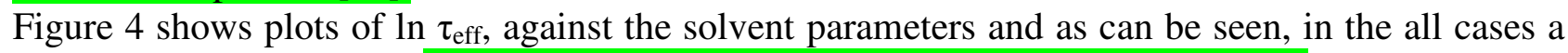
good correlation is found with the exception of the measurements done in toluene. This behaviour indicates that proticity is an important factor in the spin exchange process, thereby explaining the lack of correlation with toluene, and suggests that breakage and formation of hydrogen bonds are likely to be involved during the conformational changes of the biradicals. Such bonds may be formed with the solvent both by the nitroxide groups as well as by the functional groups that are present in the bridges of several of the biradicals.
\end{abstract}

[insert Figure 4 about here]

The longitudinal relaxation time, $\tau_{\mathrm{L}}$, of a solvent is given as $\tau_{\mathrm{L}}=\left(\varepsilon_{\infty} / \varepsilon_{\mathrm{S}}\right) \tau_{\mathrm{D}}$, using its Debye relaxation time, $\tau_{\mathrm{D}}$, together with the static and infinite frequency permittivities, $\varepsilon_{\mathrm{S}}$ and $\varepsilon_{\infty}$. Values of $\tau_{\mathrm{D}}$ and $\varepsilon_{\mathrm{S}}$ are usually available with good precision, but $\varepsilon_{\infty}$ is often determined using 
extrapolations and, if at all, is known with less precision. Therefore it is common practice to use the approximation $\varepsilon_{\infty} \approx \mathrm{n}_{\mathrm{D}}^{2}$, where $\mathrm{n}_{\mathrm{D}}$ is the refractive index of the solvent.

For some solvents, multiple relaxation pathways have been reported, each having an associated $\tau_{\mathrm{L}}$. Water and lower alcohols are good examples of such solvents, since two relaxation times are found. The longer of these is attributed to hydrogen bond kinetics, which is associated with the breakage of hydrogen bonds in the immediate vicinity of the solute. The shorter time has been suggested to account for more localised fluctuations that happen during the continuous 'realignment' of hydrogen bonds that occur in the bulk of the solution [38]. In investigations on intermolecular exchange, where $\tau_{\mathrm{L}}$ is known to play an important role $[39,40]$, it is assumed that only the longest relaxation time will influence the reaction, since all shorter ones are expected to be outside its time scale. The plots of $\ln \tau_{\text {eff }}$ vs. $\ln \tau_{\mathrm{L}}$ in figure 4 show a clear correlation between the two parameters for these biradicals. This further supports the idea that hydrogen bond dynamics are important to the chemical exchange observed in the three biradicals. The results show that effective hydrogen bond formation, i.e. when $\alpha$ is large and $\tau_{\mathrm{L}}$ short, leads to lower values of $\tau_{\text {eff }}$ and thus promotes the exchange process.

The result obtained in bmimPF $_{6}$ shows a poor correspondence with those of the alcohols when concerned with polarity. This is likely due to the ionic structure of the liquid as compared to the uncharged dipole of the alcohols. Conversely, the remarkably good correlation when investigating hydrogen bonding suggests that the effect from hydrogen bonding is having a stronger influence on the chemical exchange than that of polarity.

In biradicals IV-VI, which have only one or two conformations, the magnitude of the exchange integral, $J$ or $\bar{J}$ respectively, can be determined experimentally from the line positions of the ESR spectra. In a recent study, including $\mathbf{V}$, it has been reported that the interaction of polar solvent molecules with the $>\mathrm{N}-\mathrm{O}$. groups of the nitroxide biradicals leads to a slight decrease of the value of $J$, parallel with slight decrease of values of the hyperfine splitting constant, with increasing temperature [17]. In contrast, interaction of polar solvent molecules with the $>S=O$ group inside the bridge connecting two radical fragments, results in noticeable increase of $|J / a|$ vs. $T$, antibatic to a slight decrease of $|a|$ values. Such different behaviour allows one to distinguish between complexation of polar solvent molecules to the $>\mathrm{S}=\mathrm{O}$ group in the bridge and their coordination to the $>\mathrm{N}-\mathrm{O}$. groups of the ring [17]. A more detailed study of solvent effects on the intramolecular spin exchange can be done by comparing the experimentally determined exchange integrals with the various solvent parameters as well.

\section{[insert Figure 5 about here]}

This is shown in Figure 5 and overall it shows how the exchange integral of biradicals is influenced differently by the solvent depending on the composition of the biradical bridge. In general, biradicals IV and VI show significant changes of opposite behaviour, whereas $\mathbf{V}$ shows a much weaker dependence. The values of $J$ for $\mathbf{I V}$, which has only alkyl groups in the bridge increase with $\pi^{*}$, thus describing the interactions between the solvent and the nitroxide groups of the biradical expressed in terms of polarity. The fact that VI shows an opposite behaviour supports the results obtained from the temperature dependences mentioned above.

These observations are reflected when comparing the results from IV and VI with $\alpha$ and $\tau_{\mathrm{L}}$ as well, hereby indicating that formation of hydrogen bonds between $>\mathrm{N}-\mathrm{O}$. groups and molecules of solvent takes place. For $\mathbf{V}$, the value of $J$ does practically not depend on the three solvent parameters. At most, it has a slight tendency towards the behaviour seen for VI. Since there is no reason for the interaction between nitroxide group and solvent to disappear, the observed result is likely due to compensation by the interaction between solvent molecules and the $-\mathrm{S}-\mathrm{O}-$ group in the bridge. Not having the $>\mathrm{S}=\mathrm{O}$ group in the bridge, and thereby being more flexible than $\mathbf{V}$, biradical VI has a more open structure which allows for better coordination to solvent molecules, and as a consequence, is more unobstructed to formation of hydrogen bonds. Therefore, the interaction between solvent molecules and the functional group in the bridge is largest in this case. 


\section{Summary}

The exchange integral, $J$, in short biradicals and the characteristic time, $\tau_{\text {eff }}$, describing the exchange between different conformations of longer biradicals were found to depend strongly on the solvent used. This was seen not only on a macroscopic level, where the bulk properties of the solvent are important but, but additionally, on a microscopic one, where the specific solvent properties are relevant. Relationships were investigated between the experimentally determined $J$ and $\tau_{\text {eff }}$ and solvent viscosity $\eta$, the Kamlet/Taft solvent parameters $\pi^{*}$ and $\alpha$, and finally, the longitudinal relaxation time $\tau_{\mathrm{L}}$.

For the long flexible biradicals, I-III, the macroscopic influence of the solvent was seen in the form of clear linear trends in plots concerning viscosity and polarity, with some degree of deviation

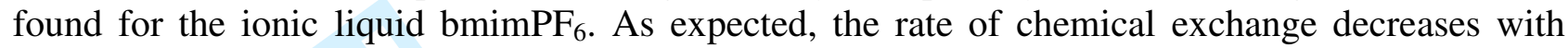
increasing viscosity. Additionally, comparisons with $\pi^{*}$ showed that the rate of exchange increases with the polarity of the solvent.

The shorter biradicals IV and VI, which both have two conformations, show a dependence of the time averaged exchange integral on both viscosity and polarity, but no chemical exchange could be detected (the line widths did not change noticeably). This shows that there are two opposite effects caused by interactions from solvent molecules, one to the functional group in the bridge and the other to the radical fragments. In IV only the latter can be observed since the bridge does not contain hetero atoms. In the case of $\mathbf{V}$ only slight changes in $J$ were observed, meaning that the interaction between solvent and bridge is less pronounced than for VI. This is believed to be due to the more constrained geometry of $\mathbf{V}$, which lowers the accessibility of its bridge to solvent molecules.

Evidence of the formation of hydrogen bonds with the solvent was found for all biradicals. The effective times of I-III were seen to decrease with increasing hydrogen bond formation capability, which seems to be linked with fast relaxations in the solvent. This suggests that the movement within the solvent cage is assisted by the breaking and formation of hydrogen bonds. Measurements in bmimPF $_{6}$ even indicated that this effect is more important to the rate of exchange than the macroscopic solvent parameters. The results obtained from IV-IV showed that hydrogen bonds are formed both with the nitroxide groups of the biradicals and with the hetero atoms of the bridges.

\section{Acknowledgment}

V.A.T would like to thank ASEA Uninet for a scholarship

\section{Reference}

1. V.N. Parmon, A.I. Kokorin, G.M. Zhidomirov. In Stable Biradicals, Nauka, Moscow (1980)

2. I.A. Grigor'ev, S.A. Dikanov, A.Z. Gogolev, L.B. Volodarsky. Izv. Sib. Otd. AN SSSR, 5, 95 (1988)

3. A. Nakajima, H. Ohya-Nishiguchi, Y. Deguchi. Bull. Chem. Soc. Japan, 45, 713 (1972)

4. V.N. Parmon, A.I. Kokorin, G.M. Zhidomirov, K.I. Zamaraev. Mol. Phys., 26, 1565 (1973)

5. E. Alster, B.L. Silver. Mol.. Phys., 58, 977 (1986)

6. V.N. Parmon, A.I. Kokorin, K.I. Zamaraev. Izv. AN SSSR, Ser. khim., 8, 1776 (1976)

7. E.K. Metzner, L.J. Libertini, M. Calvin. J. Amer. Chem. Soc., 96, 6515 (1974)

8. V.I. Gulin, S.A. Dikanov, V.V. Martin, I.A. Grigor'ev, L.B. Volodarsky. Izv. Sib. Otd. AN SSSR, Ser. Khim. Nauk (2), 5, 99 (1988)

9. Yu.N. Molin, K.M. Salikhov, K.I. Zamaraev. In Spin Exchange, Springer, Berlin (1980)

10. E.K. Metzner, L.J. Libertini, M. Calvin. J. Amer. Chem. Soc., 96, 6515 (1974)

11. R. Briere, H. Lemaire, A. Rassat. Bull. Soc. Chim. France, 3273 (1965)

12. O.H. Griffith, P.J. Dehlingert, S.P. Van. J. Memb. Biol., 15, 159 (1974)

13. H. Hayat, B.L. Silver. J. Phys. Chem., 77, 72 (1973) 
Table 1. Physical properties of solvents at $298 \mathrm{~K}$.

\begin{tabular}{ccccc}
\hline Solvent & $\tau_{\mathrm{L}}, \mathrm{ps}^{\mathrm{a}}$ & $\eta, \mathrm{cP}^{\mathrm{b}}$ & $\pi^{*^{\mathrm{c}}}$ & $\alpha^{\mathrm{c}}$ \\
\hline Methanol & 9.36 & 0.551 & 0.60 & 0.99 \\
Ethanol & 30.1 & 1.08 & 0.54 & 0.86 \\
Propanol & 41.0 & 2.10 & 0.52 & 0.84 \\
Butanol & 61.8 & 2.57 & 0.47 & 0.84 \\
Hexanol & 182 & 4.55 & 0.40 & 0.80 \\
Octanol & 268 & 7.36 & 0.40 & 0.77 \\
Cyclohexanol & 611 & 41.3 & 0.45 & 0.66 \\
Toluene & 6.90 & 0.553 & 0.51 & 0 \\
BmimPF6 & $141^{\mathrm{d}}$ & $257^{\mathrm{e}}$ & $0.94^{\mathrm{f}}$ & $0.76^{\mathrm{f}}$ \\
\hline${ }^{\mathrm{a}}$ Data are taken from $[20],{ }^{\mathrm{b}}$ from $[29],{ }^{\mathrm{c}}$ from[32], ${ }^{\mathrm{d}}$ from [26], ${ }^{\mathrm{e}}$ from [27], ${ }^{\mathrm{f}}$ from [28]
\end{tabular}

Table 2. Experimentally determined data on the investigated biradicals.

\begin{tabular}{cccccccc}
\hline \multirow{2}{*}{ Solvent } & \multicolumn{4}{c}{$\tau_{\text {eff }} / \mathrm{ns}^{\mathrm{a}}$} & & \multicolumn{3}{c}{$J / \mathrm{MHz}^{\mathrm{a}}$} \\
\cline { 2 - 4 } \cline { 6 - 7 } & $\mathrm{I}$ & $\mathrm{II}$ & $\mathrm{III}$ & & IV & V & VI \\
\hline Methanol & 4.0 & 2.0 & 0.78 & & 627 & 1760 & 96,2 \\
Ethanol & 6.8 & 2.8 & - & & - & 1720 & 90,3
\end{tabular}

4. A.B. Shapiro, V.N. Parmon, V.V. Pavlikov, V.I. Rubtsov, E.G. Rozantsev. Izv. AN SSSR, Ser. khim., 2, 449 (1980)

15. A.I. Kokorin. Appl. Magn. Reson., 26, 253 (2004)

16. I.A. Grigor'ev, S.A. Dikanov, G.I. Shchukin, L.B. Volodarsky, Yu.D. Tsvetkov. Zh. Strukt. Khimii, 23, 565 (1982)

17. A.I. Kokorin, V. A. Tran, K. Rasmussen, G. Grampp. Appl. Magn. Reson. 30, 35 (2006)

18. G. Grampp, S. Landgraf, I.A. Grigor'ev, A.B. Shapiro, A.I. Kokorin. Appl. Magn. Reson., 19, 187 (2000)

19. G. Grampp, K. Rasmussen, A.I. Kokorin. Appl. Magn. Reson, 26, 245 (2004)

20. V. A. Tran, K. Rasmussen, G. Grampp, A.I. Kokorin. Appl. Magn. Reson. 32, (2007) in press

21. E. G. Rozantsev, V. I.Suskina. Izv. AN SSSR, 2148 (1968)

22. A. B. Shapiro, M. G. Goldfield, E. G. Rozantzev. Tetrahedron Let., 2183 (1973)

23. A. B. Shapiro, V. I. Suskina, Izv. AN SSSR, 1900 (1986)

24. A. B. Shapiro, V. I. Suskina, V. V. Fedorova, E. G. Rozantsev. Izv. AN SSSR, 694 (1970)

25. K. A. Fletcher, I. A. Storey, A. E. Hendricks, S. Pandey, S. Pandey. Green Chem., 210 (2001)

26. J.A. Riddick, W.B. Bunger, K.T. Sakano. In Techniques of Chemistry. Vol. II: Organic

Solvents, Physical Chemistry and Methods of Purification, Wiley, New York (1986)

27. S. N Baker, G. A. Baker, F. V. Bright. Green Chem., 4, 165 (2002)

28. A. J. McLean, M. J. Muldoon, C. M. Gordon, I. R. Dunkin. Chem. Commun., 1880 (2002)

29. N. Ito, R. Richert. J. Phys. Chem. B, 111, 5016 (2007)

30. H. Lemaire. J. Chem. Phys, 64, 559 (1967)

31. V. N. Parmon, A. I. Kokorin, G. M. Zhidomirov, K. I. Zamaraev. Mol. Phys., 30, 695 (1975)

32. A.L. Buchachenko, A.M. Wasserman. In Stable Radicals, Khimiya, Moscow (1973)

33. R. Gilmont. Measurement \& Control, 10, 36 (2002)

34. C. Reichard. Chem. Rev., 94, 2319 (1994)

35. Kamlet, J. Am. Chem. Soc., 98, 2886 (1976)

36. Y.Marcus. In The Properties of Solvents, Wiley, England (1998)

37. K.N. Marsh, J.A. Boxall, R. Lichtenthaler. Fluid Phase Equilibria. 219, 93 (2004)

38. J. Barthel, R. Buchner, M. Munsterer. In: Chemistry Data Series. Vol, XII, Part 2a.: Electrolyte

Data Collection, Dechema, Germany (1996)

39. G. Grampp, W. Jaenicke. Ber. Bunsenges. Phys. Chem., 95, 904 (1991)

40. G. Grampp, K. Rasmussen. Phys. Chem. Chem. Phys., 22, 5546 (2002)

${ }^{a}$ Data are taken from [20], ${ }^{b}$ from [29], ${ }^{\mathrm{c}}$ from[32], ${ }^{\mathrm{d}}$ from [26], ${ }^{\mathrm{e}}$ from [27], ${ }^{\mathrm{f}}$ from [28] 


\section{Captions to the Figures:}

Figure 1. Structures of the radical fragments appearing in the studied biradicals.

Figure 2. (a) Typical ESR spectra of the six biradicals in toluene at 298K. (b) ESR spectra of $\mathbf{I}$ in bmimPF $_{6}$ at various temperatures.

Figure 3. Dependence of the experimental parameters $\ln J$ and $\ln \tau_{\text {eff }}$ on viscosity of different solvents at $298 \mathrm{~K}$.

Figure 4. Dependence of $\ln \tau_{\text {eff }}$ for biradicals I ( $\square$ ), II (०), and III ( $\Delta$ ) at $298 \mathrm{~K}$ on the Kamlet/Taft solvent parameters $\alpha$ and $\pi^{*}$ and on the longitudinal relaxation time, $\tau_{\mathrm{L}}$. The arrow indicates values belonging to measurements done in toluene.

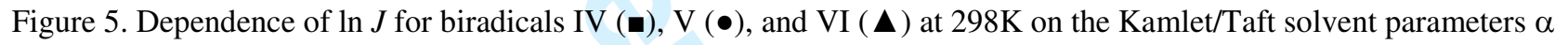
and $\pi^{*}$ and on the longitudinal relaxation time, $\tau_{\mathrm{L}}$. The arrow indicates values belonging to measurements done in toluene. 
Figure 1<smiles>[R]N1C(C)(C)CC(C)CC1(C)C</smiles><smiles>[R]ON1C(C)(C)C=C(C)CC1(C)C</smiles> 
Figure 2

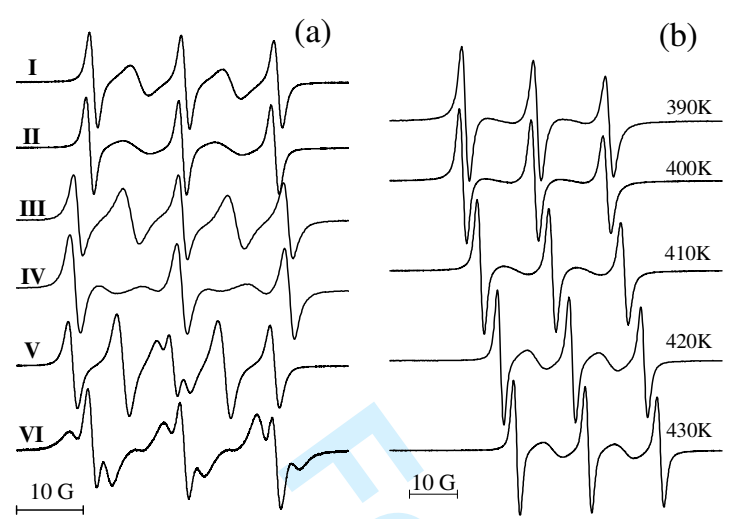


Figure 3
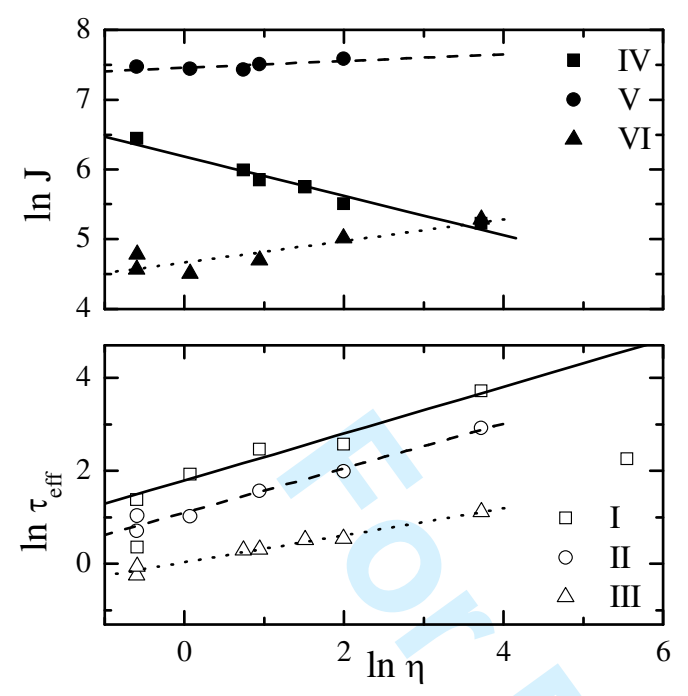
Figure 4
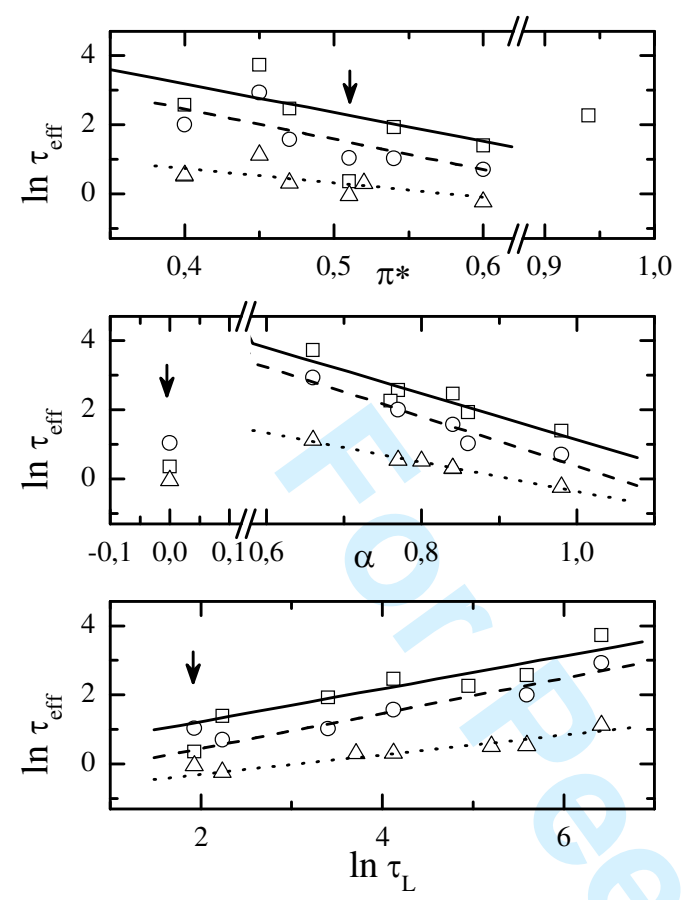
Figure 5
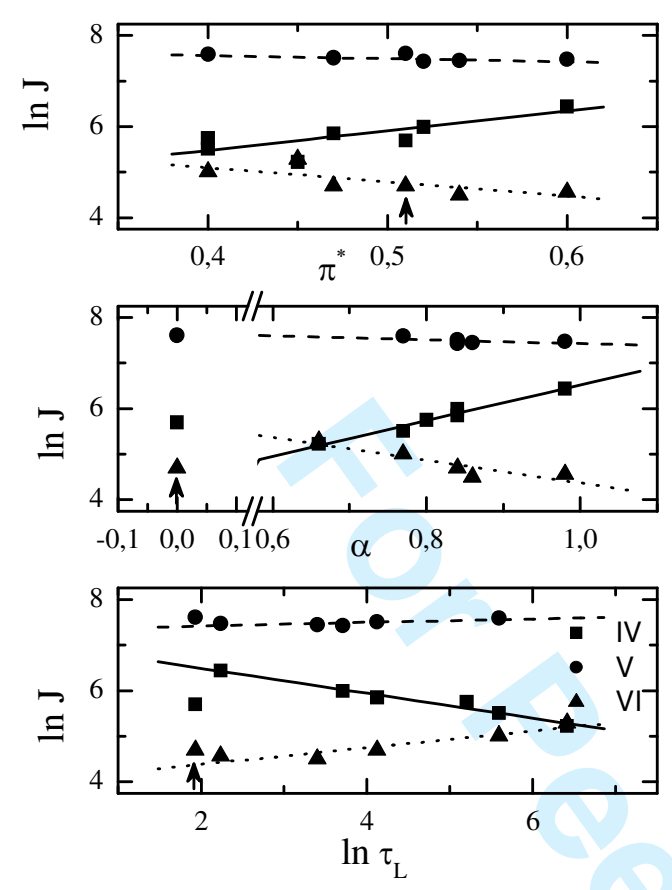